INVESTIGACIÓN

Recibido: 08/06/2020 --- Aceptado: 19/06/2020 --- Publicado: 12/03/2021

\title{
ANÁLISIS DE LAS PUBLICACIONES DE LA CUENTA DE INSTAGRAM DEL MINISTERIO DE ASUNTOS EXTERIORES Y COOPERACIÓN, DESDE UNA PERSPECTIVA DE GÉNERO
}

\section{Analysis of the publications of the Instagram account of the Ministry of Foreign Affairs and Cooperation, from a gender perspective}

(8) Laura Romero-Vara. Universidad Complutense de Madrid. España. Laurom05@ucm.es

Alicia Parras-Parras. Universidad Complutense de Madrid. España. aparras@ucm.es

\section{RESUMEN}

Introducción: El presente estudio de carácter cualitativo y cuantitativo busca identificar las acciones que lleva a cabo el gobierno de España para fomentar y promover la igualdad de género en el propio país y alrededor del mundo. Metodología: Se lleva a cabo un análisis de contenido de las publicaciones encontradas en la cuenta de Instagram del MAEC (Ministerio de Asuntos Exteriores y Cooperación) descubriendo así la importancia que le otorgan las instituciones españolas a este tema. Para lograr ese objetivo, se han analizado los 861 posts de Instagram publicadas a partir del 11 de marzo de 2016, fecha de la en la que aparece la primera publicación, hasta el 30 de noviembre de 2019. La hipótesis central es que dos sucesos importantes ocurridos en España en el 2018 -la huelga feminista del 8M y la moción de censura del expresidente Rajoy- han favorecido que el gobierno preste más atención a la igualdad de género y por tanto, aumente el número de publicaciones respecto a esta temática. Discusión y resultados: en torno a cuatro ejes (interacción y engagement, las temáticas, la representación de la mujer en la cuenta de instagram @exteriores.maec y contenido audiovisual, hashtags y emojis). El nivel de interacción que tiene la cuenta de Instagram del MAEC es bajo (0,33\%). Las categorías donde se encontró un número más alto de publicaciones que incluyen la cuestión de género encontramos la utilización del lenguaje inclusivo. Se prima el uso fotografías únicas, antes que carruseles $(24,66 \%)$ o vídeos $(12 \%)$ y en el periodo y muestra analizada, cabe destacar que en un $74 \%$ del contenido audiovisual relacionado con la igualdad de género encontrado en la cuenta de Instagram del MAEC es posible encontrar presencia femenina. Conclusiones: Aunque en el último par de años se puede observar un aumento considerable en las publicaciones 
Análisis de las publicaciones de la cuenta de Instagram del ministerio de asuntos exteriores y cooperación, desde una perspectiva de género

relacionadas con la igualdad de género en la cuenta de Instagram del MAEC, siguen siendo pocas y se centran principalmente en la celebración o conmemoración alrededor de fechas clave como es el Día Internacional de la Mujer o el Día Internacional de la Eliminación de la Violencia contra la Mujer.

PALABRAS CLAVE: igualdad de género - diplomacia digital; ODS2030 - Ministerio de Asuntos Exteriores y Cooperación - feminismo -8-M - Gobierno de España.

\section{ABSTRACT}

Introduction: This qualitative and quantitative study seeks to identify the actions carried out by the government of Spain to promote and promote gender equality in the country itself and around the world. Methodology: A content analysis of the publications found on the MAEC Instagram account is carried out, thus discovering the importance that Spanish institutions attach to this topic. To achieve this goal, the 861 Instagram posts published as of March 11, 2016, date from which the first publication appears, have been analyzed until today November 30, 2019. The central hypothesis is that two important events occurred in Spain in 2018: the 8M feminist strike and the motion of censure by former President Rajoy have favored that the government pay more attention to gender equality and, therefore, increase the number of publications regarding this theme. Discussion and results: around four axes (interaction and engagement, the themes, the representation of women in the Instagram account @exterior.maec and audiovisual content, hashtags and emojis). The level of interaction of the MAEC Instagram account is low $(0.33 \%)$. The categories where a higher number of publications were found that include the gender issue include the use of inclusive language; The use of unique photographs is preferred, before carousels $(24.66 \%)$ or videos $(12 \%)$ and in the period and sample analyzed, it should be noted that in $74 \%$ of the audiovisual content related to gender equality found in the account From MAEC's Instagram it is possible to find a female presence. Conclusions: Although in the last couple of years a considerable increase in publications related to gender equality can be observed on the MAEC Instagram account, they are still few and mainly focus on celebrating or commemorating around key dates such as it is International Women's Day or International Day for the Elimination of Violence against Women.

KEY WORDS: gender equality - digital diplomacy - SDGs2030 - Ministry of Foreign Affairs and Cooperation - feminism - 8-M - Spanish Government.

\section{ANÁLISE DAS PUBLICAÇÕES DA CONTA DO INSTAGRAM DO MINISTÉRIO DE RELAÇÕES EXTERIORES E COOPERAÇÃO, DESDE UMA PERSPECTIVA DE GÊNERO}

\section{RESUMO}

Introdução: $\mathrm{O}$ presente estudo de caráter qualitativo e quantitativo procura 
Análisis de las publicaciones de la cuenta de Instagram del ministerio de asuntos exteriores y cooperación, desde una perspectiva de género

identificar as ações que são feitas pelo governo da Espanha para fomentar e promover a igualdade de gênero no próprio país e ao redor do mundo. Metodologia: Foi feita uma análise de conteúdo das publicações encontradas na conta do Instagram do MAEC (Ministério de Relações Exteriores e Cooperação pelas siglas em espanhol) descobrindo assim a importância que lhes são dadas as instituições espanholas a este tema. Para atingir este objetivo, foram analisados os 861 posts do Instagram publicados a partir do 11 de março de 2016, data na que aparece a primeira publicação, até 30 de novembro de 2019. A hipótese central é que dois acontecimentos importantes acontecidos na Espanha no ano de 2018 -a greve feminista de $8 \mathrm{M}$ e a moção de censura do expresidente Rajoy- favoreceram que o governo desse mais atenção referente a igualdade de gênero e como resultado temos um aumento no número de publicações sobre esta temática. Discussão e resultados: ao redor de quatro eixos (interação e engagement, temáticas, representação da mulher na conta de instagram @exteriores.maec e conteúdo audiovisual, hashtags e emojis). O nível de interação que a conta do Instagram do MAEC tem é baixo $(0,33 \%)$. As categorias onde existe um número maior de publicações que inclui a discussão de gênero encontramos a utilização da linguagem inclusiva. Se dá prioridade ao uso de fotografias únicas, e não a carrossel (24,66\%) ou vídeos (12\%) e no período e amostra analisada, é importante destacar que $74 \%$ do conteúdo audiovisual relacionado com a igualdade de gênero encontrado na conta do Instagram do MAEC pode-se observar um aumento considerável nas publicações relacionadas com a igualdade de gênero, continua sendo uma pequena quantidade e estão principalmente relacionadas às celebrações e comemorações de datas importantes como o Dia Internacional da Mulher ou o Dia Internacional do combate a Violência contra a Mulher.

\section{PALAVRAS CHAVE}

Igualdade de gênero - Diplomacia digital; ODS2030 - Ministério de Relações Exteriores e Cooperação - Feminismo -8-M - Governo de Espanha.

\section{Cómo citar el artículo:}

Romero-Vara, L. y Parra-Parra, A. (2021). Análisis de las publicaciones de la cuenta de Instagram del ministerio de asuntos exteriores y cooperación, desde una perspectiva de género. Vivat Academia. Revista de Comunicación, 154, 1-24. http:/ / doi.org/10.15178/va.2021.154.e1245

http://www.vivatacademia.net/index.php/vivat/article/view/1245

\section{INTRODUCCIÓN}

En 1915 la I Guerra Mundial se encontraba en pleno auge cuando un grupo de distintas organizaciones y más de 15.000 mujeres de doce países del mundo llevaron a cabo, pese a los obstáculos que la movilización en esos tiempos suponía, el Congreso Internacional de las Mujeres en La Haya. Este encuentro tenía como 
objetivo principal proponer iniciativas para el establecimiento de una paz duradera; "un cambio de rumbo en la política internacional con acuerdos entre gobiernos y organismos internacionales que establezcan los principios necesarios para el mantenimiento de la paz" (Rabaneda y Martínez, 2015, p.195). A raíz de lo propuesto en el congreso, se generaron una serie de propuestas encaminadas principalmente a instaurar la paz mundial, pero que ya incluían conceptos tan actuales como la cooperación internacional, la solidaridad, el arbitraje y conciliación, la educación en la cultura de paz, la inclusión de las mujeres en la toma de decisiones internacionales y el desarme general. E incluso pensaron en la creación de una Asociación de Naciones. Lamentablemente, ninguna de estas propuestas fue escuchada en su momento por los hombres que se encontraban en el poder, que tildaron el encuentro de hermandades de pacifistas y soñadoras. Sin embargo, las resoluciones adoptadas por las mujeres congregadas en dicha iniciativa han sido la base de las relaciones internacionales modernas (Tickner, 2018, p.223) y que, incluso, inspiraron al presidente norteamericano Woodrow Wilson en la elaboración de los famosos "Catorce Puntos" que presentó ante el congreso de Estados Unidos en enero de 1918 (Rabaneda y Martínez, 2015, p.197).

En este artículo se plantea el uso de las redes sociales como un espacio y oportunidad para representar el movimiento feminista de los últimos años, en concreto desde el punto de vista de la diplomacia y la política exterior porque es ahí donde se desarrolla una parte importante de la vida de las sociedades modernas. Como señalan Finkel y Gordo, (2019, p.27) “las tecnologías y entornos digitales pueden construir una oportunidad para redefinir el funcionamiento de la sociedad y avanzar en igualdad social y económica". Estas redes en general - e Instagram en particular, por lo que respecta a esta investigación- son desde luego, los nuevos espacios donde se construye la identidad social de las personas y las naciones (Villaplana y León, 2019, p.290). Por esta razón y como no podía ser de otro modo, las cancillerías de exteriores también hacen uso de las ventajas que ofrecen estas redes para llevar a cabo las tareas propias de la diplomacia. A esta nueva práctica se le conoce como diplomacia digital.

En este sentido, es pertinente investigar los contenidos que se publican en las redes sociales referentes a los roles, al tiempo de palabra o simplemente a las referencias o los planos que se dedican a la presencia de las mujeres en las relaciones internacionales.

\section{ESTADO DE LA CUESTIÓN}

Si los anteriores párrafos nos sirven para dar cuenta de la influencia -poco reconocida, admitámoslo- de las mujeres en grandes decisiones sobre política internacional a principios del siglo $\mathrm{XX}$, pasemos ahora a ver de manera somera la perspectiva académica sobre las teorías feministas en el ámbito de las relaciones internacionales desde diferentes perspectivas: feminismo liberal, feminismo radical y feminismo posmoderno. Lozano Vázquez (2012, p.147) sitúa el objetivo -general- del feminismo en relaciones internacionales en el desafío del "paradigma realista y

Vivat Academia. Revista de Comunicación. 2021, n 154, 1-24 
liberal que argumentan y justifican la operación de un sistema internacional que mantiene al hombre en una posición superior y de ventaja sobre la mujer en un status quo que le es absolutamente desfavorecedor y opresivo". Otros autores, como Lyric Thompson y Rachel Clement (2019, p.7), definen la política exterior feminista como:

la política de un estado que define sus interacciones con otros estados y movimientos de manera que prioriza la igualdad de género y consagra los derechos humanos de la mujer y otros grupos tradicionalmente marginados, separa recursos significantes para alcanzar esta visión y busca interrumpir estructuras patriarcales a lo largo de todos sus niveles de influencia (asistencia, comercio, defensa y diplomacia), con su implementación informado por las voces de activistas, grupos y movimientos feministas.

Como se ha señalado, hay tres perspectivas diferentes en el estudio académico del feminismo y las relaciones internacionales. La primera perspectiva, el feminismo liberal, se remonta a los años 60 y 70 del siglo XX (Marchand, 2016, p.64) y planteaba que las mujeres eran iguales que los hombres, por lo que criticaban la subrepresentación de las mujeres en las relaciones internacionales, "desde el punto de vista feminista-liberal, la igualdad de derechos se reduce a que ambos sexos tengan el mismo número de cargos públicos" (Locher, 1998, p.6).

En segundo lugar, el feminismo radical parte del supuesto de la diferencia entre los sexos; es decir, se basa en principios dualistas (hombre-mujer, bien-mal, agresivopacífico, empatía- apatía, etc) e incluye el concepto de sociedad patriarcal como sistema que "define relaciones y mecanismos de dominación y subordinación en diferentes contextos, como la política, el mercado y la vida cotidiana" (Marchand, 2016, p.64) y daban superioridad a las cualidades femeninas para llevar a cabo las relaciones internacionales (Locher, 1998, p.7).

Y en último lugar, el feminismo posmoderno sustituye el concepto de hombremujer por el de "género" basándose en "la construcción social de las diferencias entre hombres y mujeres" (Villarroel, 2007, p.72). De esta forma sería posible reconfigurar los pilares arquitectónicos de las sociedades y según Locher (1998, p.11): "una perspectiva sensible al género ahonda mucho más, busca colocar en su punto focal esas normas e ideas en las que se basa la relación entre los sexos, para vincularlas con las acciones de los actores internacionales".

Desde el año 2000, la Organización de las Naciones Unidas (ONU) ha incorporado entre sus objetivos de desarrollo la promoción de la igualdad de género, estos objetivos han sido ratificados por 189 países (2000) y 193 países (2015). Desafortunadamente, según el informe Equal Mesures 2030 ningún Estado alcanzará el objetivo 5 en la fecha fijada. Y terminando la segunda década del siglo XXI, se toma en serio el desempeño y la valía de las mujeres en la práctica de la política exterior global; ya que históricamente las relaciones internacionales se han llevado a cabo desde una visión masculina por ser principalmente dirigidas por hombres. Y aunque la batalla no está ganada, hay algunos sectores en pocos países como por ejemplo Suecia (Stevens, 2018) o Canadá (Robertson, 2017) donde se aprecian 
grandes avances en campos que han sido considerados tradicionalmente patriarcales a lo largo de la historia: la diplomacia feminista o la práctica de una política exterior feminista, que promueve la representación de la mujer en altos cargos diplomáticos y gubernamentales, la asignación de recursos económicos a la protección de los derechos de las niñas y mujeres y la "dignidad humana" en la que además se incluyen conceptos como acceso a la salud, educación, empleo, propiedad o acción climática (Thompson y Clement, pp. 2-3).

Eliminar la brecha de género es un tema que preocupa y ocupa a las sociedades del mundo moderno. En concreto, España se ha convertido en un referente a nivel mundial del movimiento feminista donde el 8 de marzo del 2018, por primera vez, se llevó a cabo una huelga nacional feminista como conmemoración del Día Internacional de la Mujer. Esto mismo se repitió la misma fecha de 2019. Cabe recordar que entre las múltiples demandas de este movimiento están la paridad de derechos laborales entre hombres y mujeres, la eliminación del techo de cristal en todas las áreas sociales y la erradicación de la violencia machista, entre otros.

Según el reporte del Foro Económico Mundial "The Global Gender Gap 2018", España ocupa el lugar 29 de 149 países analizados en lo que respecta a paridad de género. Por su parte el informe "Equal Messures 2030" lo situaba en lugar 23 en las ediciones del 2018 y 2019. Finalmente, el "Ranking Europeo de igualdad de género", le otorga el puesto 8 de entre 36 países que conforman la UE.

En cuanto a la representación femenina en el gobierno español, tanto en el parlamento como en el senado hay aproximadamente un $40 \%$ de mujeres ocupando escaños (Tena, 2018), además, el actual gobierno de Pedro Sánchez ha incorporado a once ministras, alcanzando un $48 \%$ de presencia femenina.

\section{OBJETIVOS}

El presente artículo pretende identificar la construcción del discurso feminista por parte del MAEC en su cuenta de Instagram (@exteriores.maec). El objetivo principal de la investigación es descubrir cómo representa el MAEC la igualdad de género en su cuenta de Instagram, reconociendo las acciones de la práctica de la política exterior que muestra el gobierno español para alcanzar la igualdad de género y acabar con la violencia de género.

Además, se busca observar el papel de las mujeres en la toma de decisiones políticas, así como su participación en las relaciones internacionales a través de órganos gubernamentales $u$ organizaciones internacionales. $Y$ también es fundamental distinguir las principales representaciones que se hacen de la mujer en la cuenta de Instagram del MAEC en función de diferentes categorías propuestas por las autoras y relacionadas con el nivel de inclusión de género (Ver gráfico 1).

La hipótesis central de la que parte este artículo es que dos acontecimientos importantes ocurridos en España en el 2018, la celebración del 8-M y la llegada al 
Romero-Vara, L. y Parra-Parra, A.

Análisis de las publicaciones de la cuenta de Instagram del ministerio de asuntos exteriores y cooperación, desde una perspectiva de género

poder del gobierno socialista han sido artífices de una mayor atención del gobierno a la igualdad de género que tiene, entre otras muchas consecuencias, el aumento del número de publicaciones con presencia femenina.

Estos dos acontecimientos mencionados en el párrafo anterior merecen ser explicados brevemente para contextualizar la presente investigación. Por un lado, una marea morada inundó las calles españolas el 8 de marzo de 2018, con motivo de la lucha por la igualdad de hombres y mujeres y la erradicación de la violencia contra las mujeres, coincidiendo con la celebración del Día Internacional de la Mujer. Y por otro, la moción de censura en contra de Mariano Rajoy que tuvo lugar a mediados del 2018, permitió al socialista Pedro Sánchez acceder a la silla presidencial. Como consecuencia directa, el gobierno español adquirió un sello feminista, otorgando cargos de primer rango en los ministerios a una mayoría de mujeres. Entre las novedades, también se reinstauró el Ministerio de Igualdad.

Se pretende responder a las siguientes preguntas de investigación:

- ¿Cuál ha sido el discurso en relación con el feminismo del MAEC desde la creación de su cuenta de Instagram?

- ¿Cuándo hay información relacionada con la igualdad de género?

- ¿Cuáles son las temáticas que suscitan la aparición de contenido relacionado con el género en la cuenta de Instagram del MAEC?

- ¿Cómo se representa a la mujer en la cuenta de Instagram del MAEC?

- ¿Cuál es el contenido en Instagram referente a la igualdad de género que alcanza un mayor engagement?

\section{METODOLOGÍA}

El presente estudio de carácter cuantitativo y cualitativo se basa en un análisis de contenido de las publicaciones de la cuenta de Instagram del Ministerio de Asuntos Exteriores y Cooperación (MAEC) de España en las que las mujeres asuman algún rol. Es decir, las publicaciones deben tratar, representar o mostrar la participación de las mujeres en algún aspecto de la política exterior española, ya sea como objeto o sujeto.

De una población total de 873 publicaciones disponibles en la cuenta del MAEC de Instagram -desde el 11 de marzo del 2016, fecha de la primera publicación de la cuenta, hasta el 30 de noviembre del 2019-fecha de la última publicación disponible al cierre de la recolección de datos, se seleccionaron las publicaciones en las cuales la temática del post estuviese relacionada con el feminismo, mujeres e igualdad de género.

Para la elaboración del análisis de contenido se ha llevado a cabo una ficha de análisis con catorce categorías que se corresponden con las principales temáticas que trata el perfil del MAEC de Instagram relacionado con la paridad de género: 
Análisis de las publicaciones de la cuenta de Instagram del ministerio de asuntos exteriores y cooperación, desde una perspectiva de género

1. Agenda 2030: En el año 2012, durante la Conferencia de las Naciones Unidas sobre el Desarrollo Sostenible se crean los Objetivos para el Desarrollo Sostenible 2030, suscritos por 193 países, entre ellos España. En ellos se acuerda tomar las medidas necesarias para alcanzar la igualdad de género y empoderar a todas las mujeres y niñas.

2. Arte, Ciencia, Cultura y Deporte: aquellas publicaciones que muestren a mujeres destacadas dentro de alguno de estos campos.

3. Cooperación Internacional: aquellas publicaciones relacionadas con la AECID.

4. Derechos Humanos: conferencias, proyectos, comisiones en pro de los Derechos Humanos.

5. Día Internacional de la Mujer: aquellas publicaciones relacionadas con la conmemoración del 8 de marzo.

6. Exhibiciones/Encuentros: publicaciones relacionadas con inauguraciones, actuaciones, eventos.

7. Igualdad de Género: foros, celebraciones que abogan por ello.

8. Lenguaje Inclusivo: especialmente, en lo referido al copy del post. Para ello, se han seguido las recomendaciones de Fundéu, disponibles en: https://www.fundeu.es/lenguaje-inclusivo/

9. Mujeres en el gobierno: posts en los que aparecen representadas mujeres del gobierno.

10. ONU: reuniones y encuentros bilaterales con esta organización.

11. Reconocimiento: premios otorgados a mujeres.

12. Trabajo del MAEC: visibilización del trabajo en pro de la igualdad de género llevado a cabo por el MAEC.

13. Violencia de Género: aquellas publicaciones que visibilizan el Día Internacional contra la Violencia de Género.

14. Visitas de Estado: ministras del gobierno español en viajes de Estado o sus homólogas de otros países visitando España, pero también primeras damas de otros países y líderes femeninas internacionales.

En total se obtuvieron 151 publicaciones con las características necesarias para proceder a su análisis. A partir de este análisis de contenido, se elaboró un estudio cualitativo en el que se observaron los roles que desempeñan las mujeres en dichas publicaciones y que son:

1. Mujeres o niñas vulnerables.

2. Mujeres trabajadoras.

3. Mujeres emprendedoras o recibiendo educación o capacitación superior.

4. Mujer florero.

5. Mujeres artistas o científicas.

6. Mujeres empoderándose.

7. Mujeres en la toma de decisiones. 
Romero-Vara, L. y Parra-Parra, A.

Análisis de las publicaciones de la cuenta de Instagram del ministerio de asuntos exteriores y cooperación, desde una perspectiva de género

El estudio se completa con un análisis del tipo de formato presente en las publicaciones del MAEC, es decir, si se trata de fotografías, videos o carruseles; y por otro, si en ese contenido aparecen representadas las mujeres y la relación de la aparición de mujeres versus hombres y cómo son representadas las mujeres. El trabajo se ha complementado con un análisis de los hashtags y emojis que son utilizados en dichas publicaciones, para descubrir qué relación tienen con nuestro objeto de estudio.

Por último, en la parte cuantitativa se compara el engagement de las publicaciones con la audiencia mediante el conteo de los me gusta y los comentarios, así como la interacción de las publicaciones. Esta parte de la investigación se ha realizado con la ayuda de la plataforma FanPage.

\section{RESULTADOS}

Para ilustrar los resultados del análisis de contenido se presentan a continuación los gráficos elaborados a partir de los datos extraídos de los contenidos de las publicaciones de la cuenta de Instagram del MAEC y que se comentarán teniendo en cuenta los aspectos más interesantes.

\subsection{La interacción y el engagement}

La siguiente gráfica muestra la suma de me gusta y comentarios en base a las catorce categorías de análisis de contenido mencionadas en el apartado de metodología:

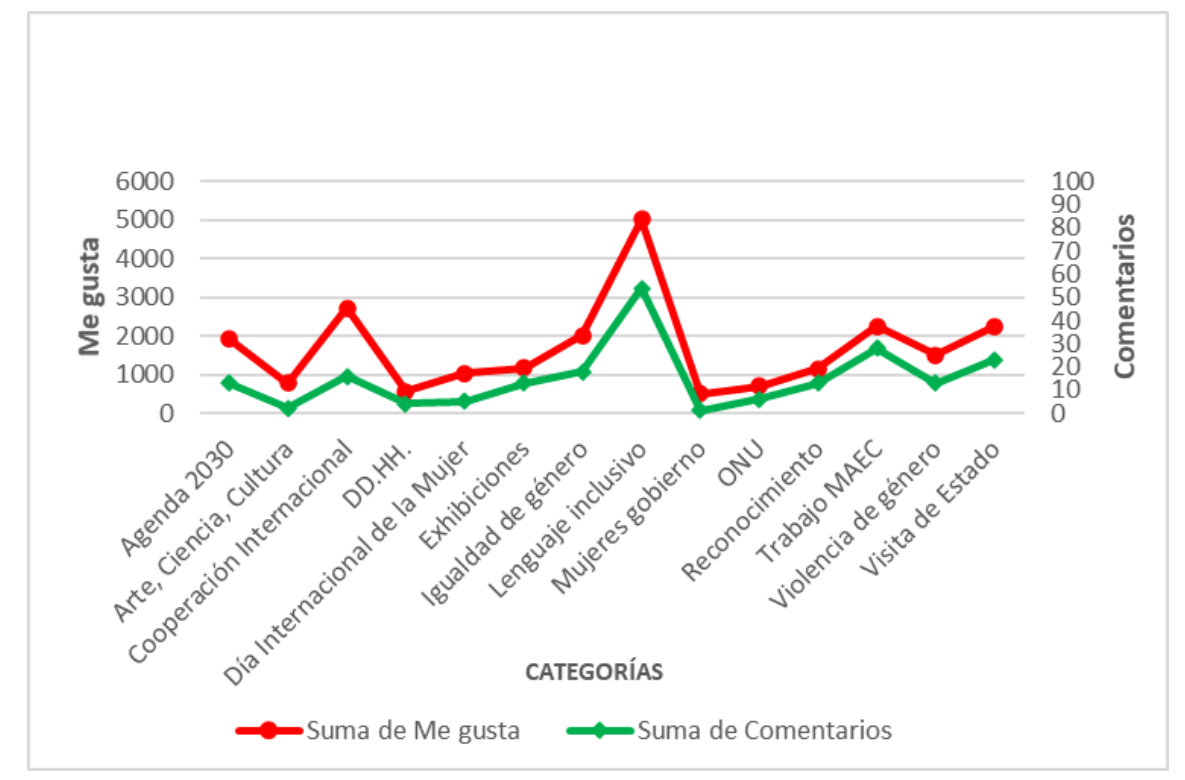

Gráfico 1. Suma de la interacción con los usuarios por temática.

Fuente: Elaboración propia 
Romero-Vara, L. y Parra-Parra, A.

Análisis de las publicaciones de la cuenta de Instagram del ministerio de asuntos exteriores y cooperación, desde una perspectiva de género

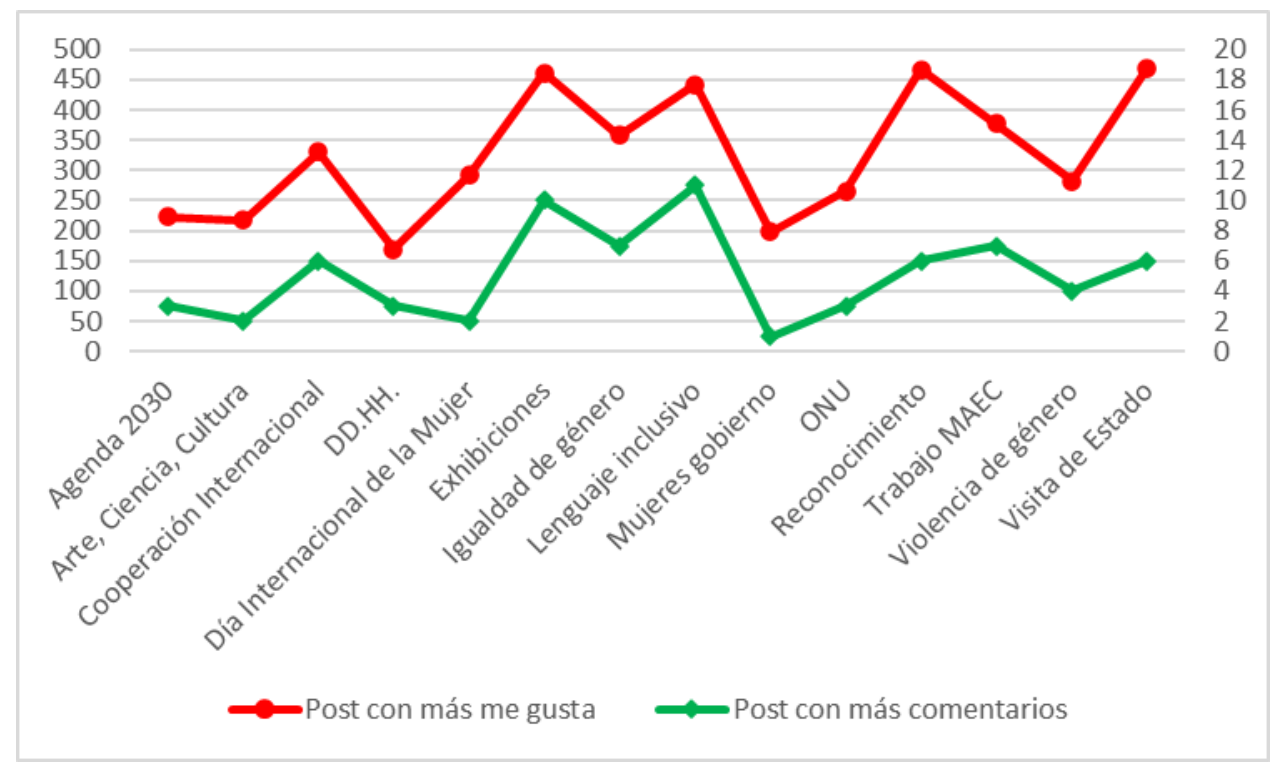

Gráfico 2. Posts con más interacción por temática.

Fuente: Elaboración propia

Para llevar a cabo el cálculo de la interacción con los usuarios, se ha utilizado la fórmula clásica:

$$
\frac{\text { núm. likes }+ \text { núm. comentarios }}{\text { núm. de seguidores }}
$$

Según el cálculo realizado, el nivel de interacción o porcentaje de audiencia a la que le gusta o comenta sus publicaciones que tiene la cuenta de Instagram del MAEC es bajo. Tan solo alcanza un $0.33 \%$ de engagement, mientras que el promedio de interacción para cuentas con menos de 1 millón de seguidores es de 2.97\% ${ }^{1}$. El MAEC tiene 23,8K seguidores a 30 de noviembre de 2019.

Sin embargo, este estudio trata de conocer cuáles son los contenidos relacionados con la igualdad de género que interesan más a los usuarios que siguen la cuenta del MAEC, ya sea porque son mayormente comentados o porque tienen un mayor número de likes (n). En este sentido, encontramos que los posts con mayor número de me gusta corresponden a la categoría de Lenguaje inclusivo ( $n=5.030, m=209,58)$; en segundo lugar, se encuentra la categoría de Cooperación internacional $(n=2.724$, $\mathrm{m}=118,43)$; y el tercer puesto es ocupado por las publicaciones relativas a las del Trabajo desempeñado en el MAEC $(n=2.254, m=187,83)$. Las categorías con mejor media $(\mathrm{m})$ de likes son Reconocimientos $(\mathrm{n}=1.157, \mathrm{~m}=289,25)$; Lenguaje inclusivo $(\mathrm{n}=5.030, \mathrm{~m}=209,58)$; y por último, Visitas de Estado $(\mathrm{n}=2.248, \mathrm{~m}=204,36)$. Es posible, dados estos datos, que la categoría que más engagement o mejor acogida tiene entre los seguidores de la cuenta del MAEC sean aquellas publicaciones analizadas relativas a la la categoría de Lenguaje inclusivo.

${ }^{1}$ https:// www.scrunch.com/blog/what-is-a-good-engagement-rate-on-instagram

Vivat Academia. Revista de Comunicación. 2021, nº 154, 1-24 
Romero-Vara, L. y Parra-Parra, A.

Análisis de las publicaciones de la cuenta de Instagram del ministerio de asuntos exteriores y cooperación, desde una perspectiva de género

Tabla 1. Categorías con mayor número de likes o me gusta en la cuenta de Instagram del MAEC en el periodo analizado.

\begin{tabular}{|l|l|l|}
\hline Tema & $\begin{array}{l}\text { Número de } \\
\text { posts }\end{array}$ & $\begin{array}{l}\text { Número (n) de } \\
\text { me gusta }\end{array}$ \\
\hline 1. Lenguaje inclusivo & 24 & 4.727 \\
\hline 2. Cooperación internacional & 23 & 2.724 \\
\hline 3. Trabajo MAEC & 12 & 2.254 \\
\hline 4. Igualdad de género & 15 & 2.012 \\
\hline 5. Agenda 2030 & 15 & 1.787 \\
\hline
\end{tabular}

Fuente: Elaboración propia

La relación entre el material audiovisual utilizado para las publicaciones y la interacción con el público apunta a que los posts que incluyen fotografías o carruseles tienen mayor interacción en lo que respecta a likes (gráfico 3). Mientras que las publicaciones con carruseles son las que mayor porcentaje proporcional y promedio de comentarios reciben (gráfico 4).

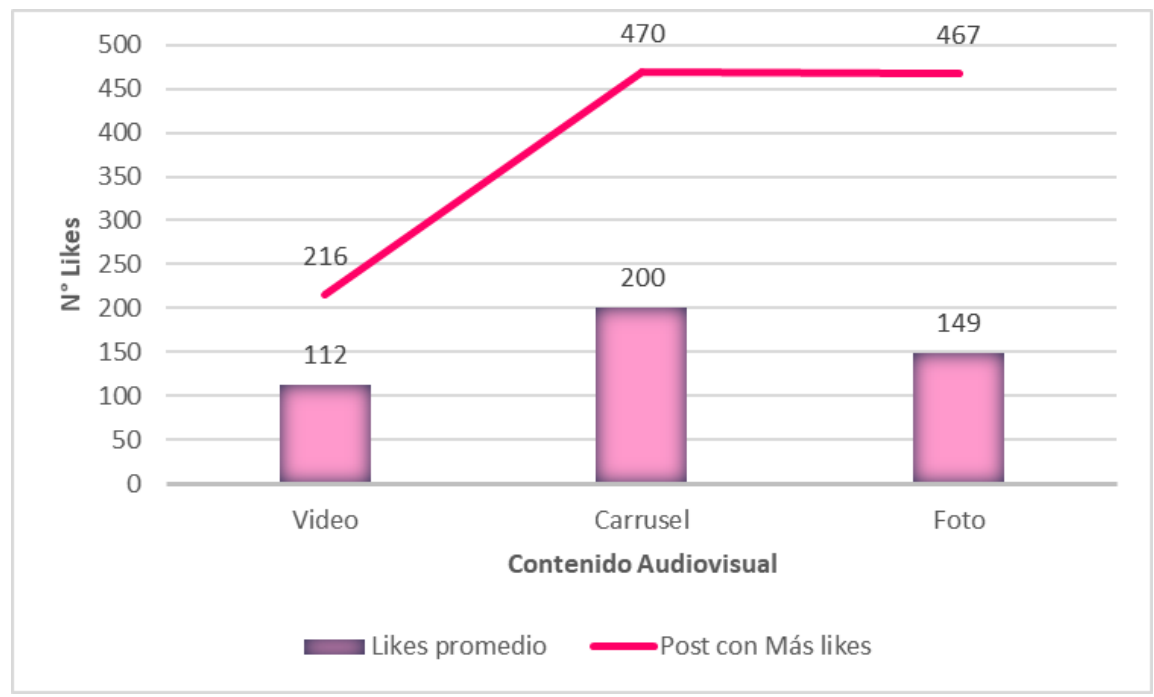

Gráfico 3. Relación de likes con el contenido audiovisual.

Fuente: Elaboración propia 
Romero-Vara, L. y Parra-Parra, A.

Análisis de las publicaciones de la cuenta de Instagram del ministerio de asuntos exteriores y cooperación, desde una perspectiva de género

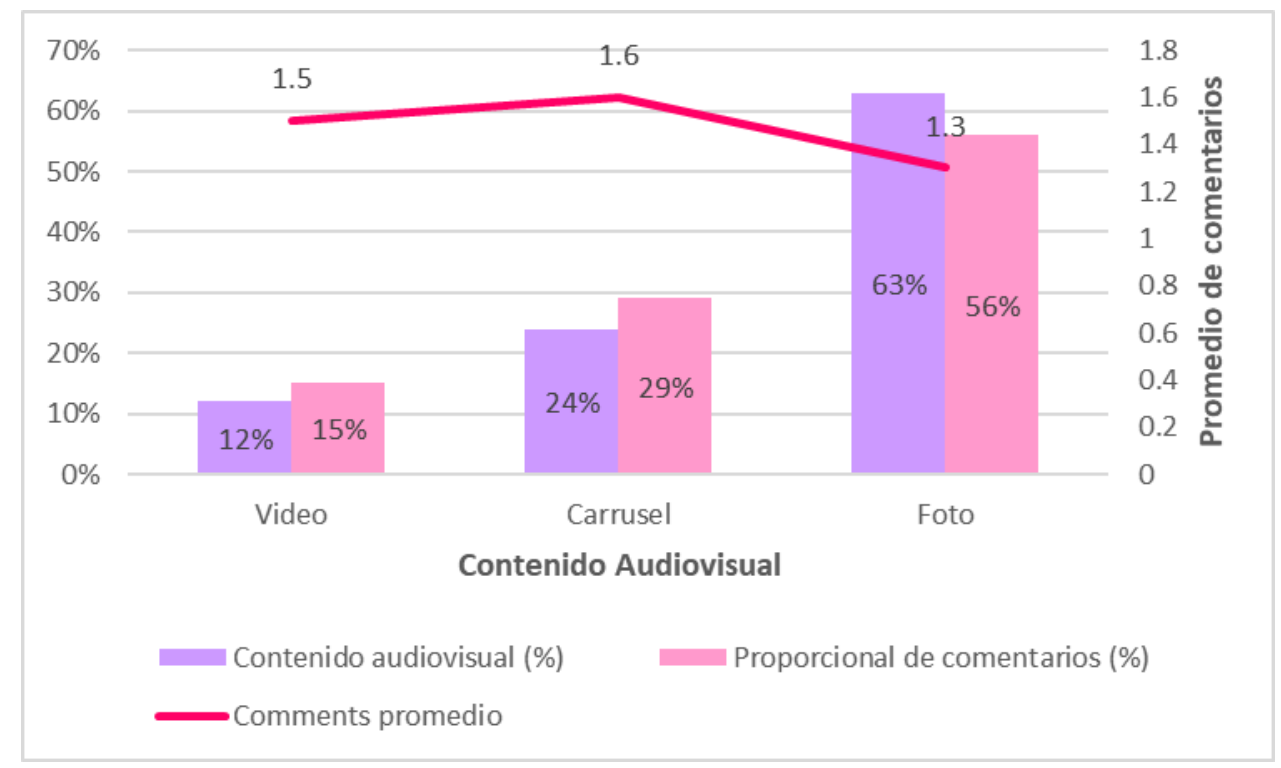

Gráfico 4. Relación de comentarios con el contenido audiovisual.

Fuente: Elaboración propia.

De hecho, y para ilustrar lo comentado anteriormente, la publicación que más likes obtuvo (470) y un número relativamente alto de comentarios (6), data del 26 de marzo de 2019 y corresponde a la visita de Estado del expresidente y la exprimera dama de Argentina a España, utiliza un carrusel y la representación que hace de la mujer es de "mujer florero", ya que muestra a la reina de España y a la esposa de Mauricio Macri como meras acompañantes (imagen 1).

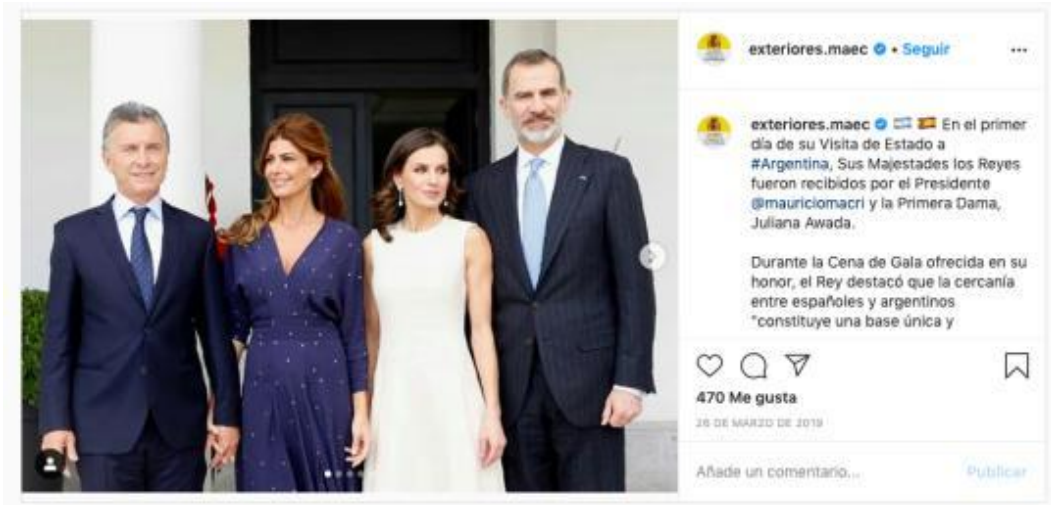

Imagen 1. Publicación del MAEC con mayor número de likes, en el periodo analizado.

Fuente: @exteriores.maec

Por otro lado, la publicación que más conversación propició entre la audiencia fue la del festejo del Día de la Comunidad de Valencia (9 de octubre de 2019) con 11 comentarios y 263 likes. Esta publicación es una fotografía de La Ciutat de les Arts i les Ciéncies envuelta en un atardecer (imagen 2). En general, la comunidad de seguidores hacía alusión al festejo y comentaba la estética de la imagen. Este contenido muestra 
Romero-Vara, L. y Parra-Parra, A.

Análisis de las publicaciones de la cuenta de Instagram del ministerio de asuntos exteriores y cooperación, desde una perspectiva de género

un lenguaje inclusivo en el texto que acompaña la imagen al felicitar a todos y todas las valencianas en su día tanto en español como en valenciano. Por tanto, se incluye dentro de la categoría de análisis de Lenguaje inclusivo.
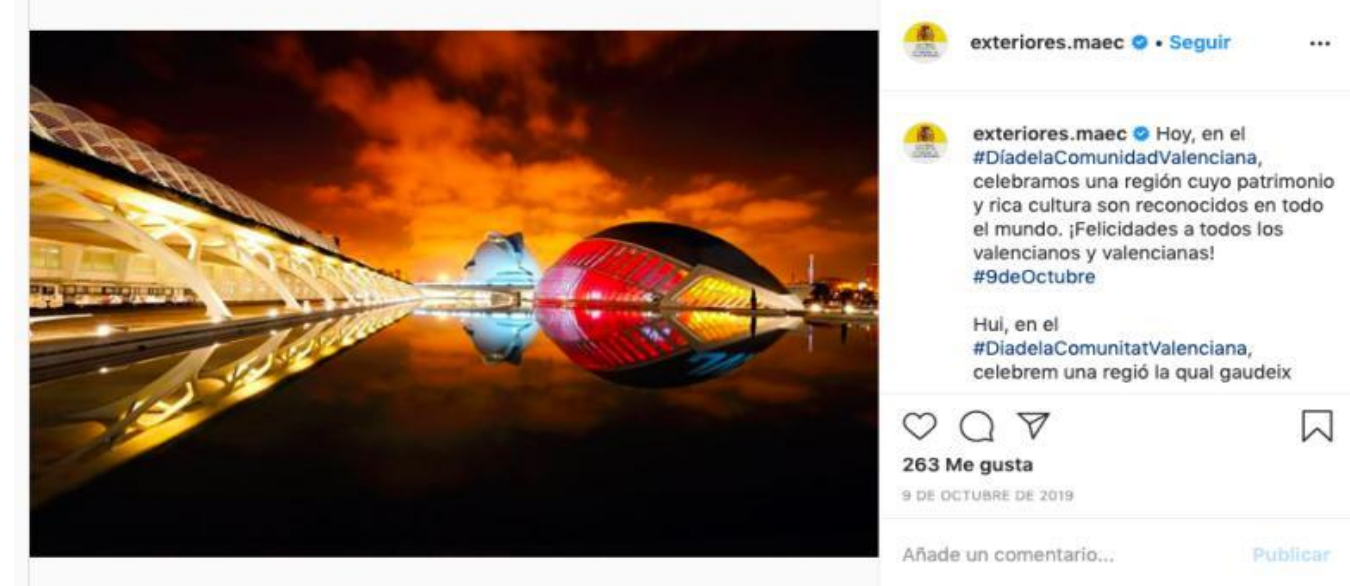

Imagen 2. Publicación del MAEC que más conversación ha propiciado en el periodo analizado.

Fuente: @exteriores.maec

En el caso de los posts en formato vídeo, la publicación que más likes (216) y comentarios (5) obtuvo en el periodo analizado es aquella que tuvo lugar el día 22 de diciembre de 2018. Esta publicación trata sobre la evolución de la mujer en la carrera diplomática y por tanto, pertenece a la categoría de análisis “Trabajo MAEC”.

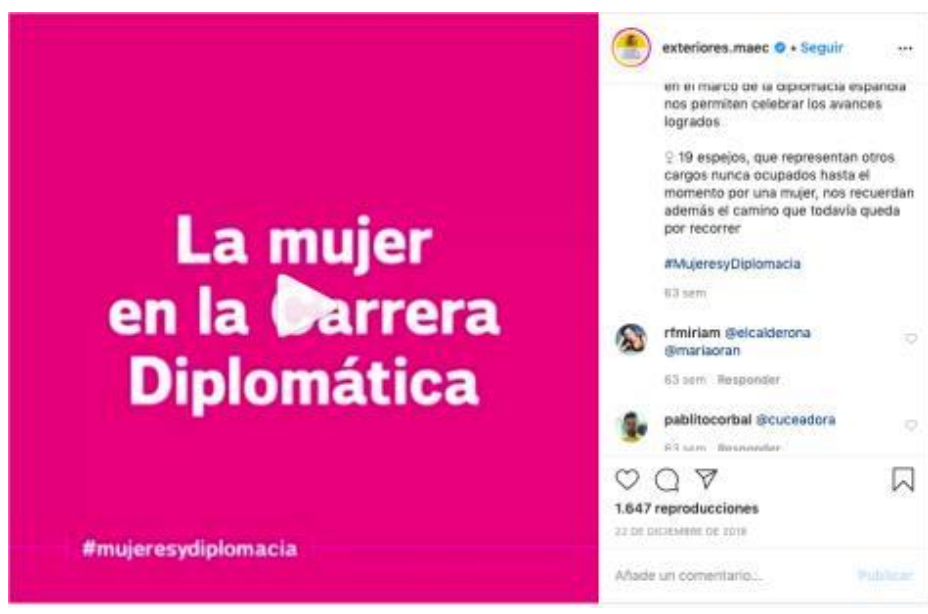

Imagen 3. Publicación del MAEC en formato video con más likes y comentarios en el periodo analizado.

Fuente: @exteriores.maec

\section{DISCUSIÓN}

\subsection{La representación de la mujer en @exteriores.maec}


El gráfico 5 nos muestra un aumento paulatino de las publicaciones referentes a la representación de la mujer en la cuenta de Instagram del MAEC:

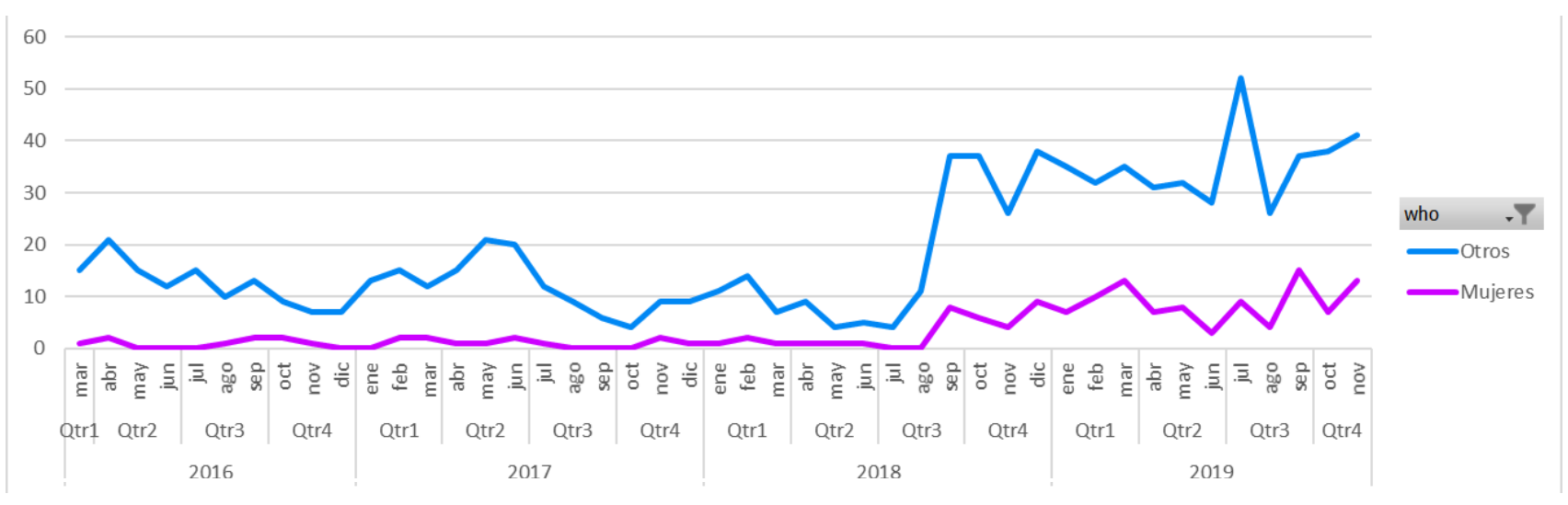

Gráfico 5. Representación de géneros en la cuenta de Instagram del MAEC.

Fuente: Elaboración propia.

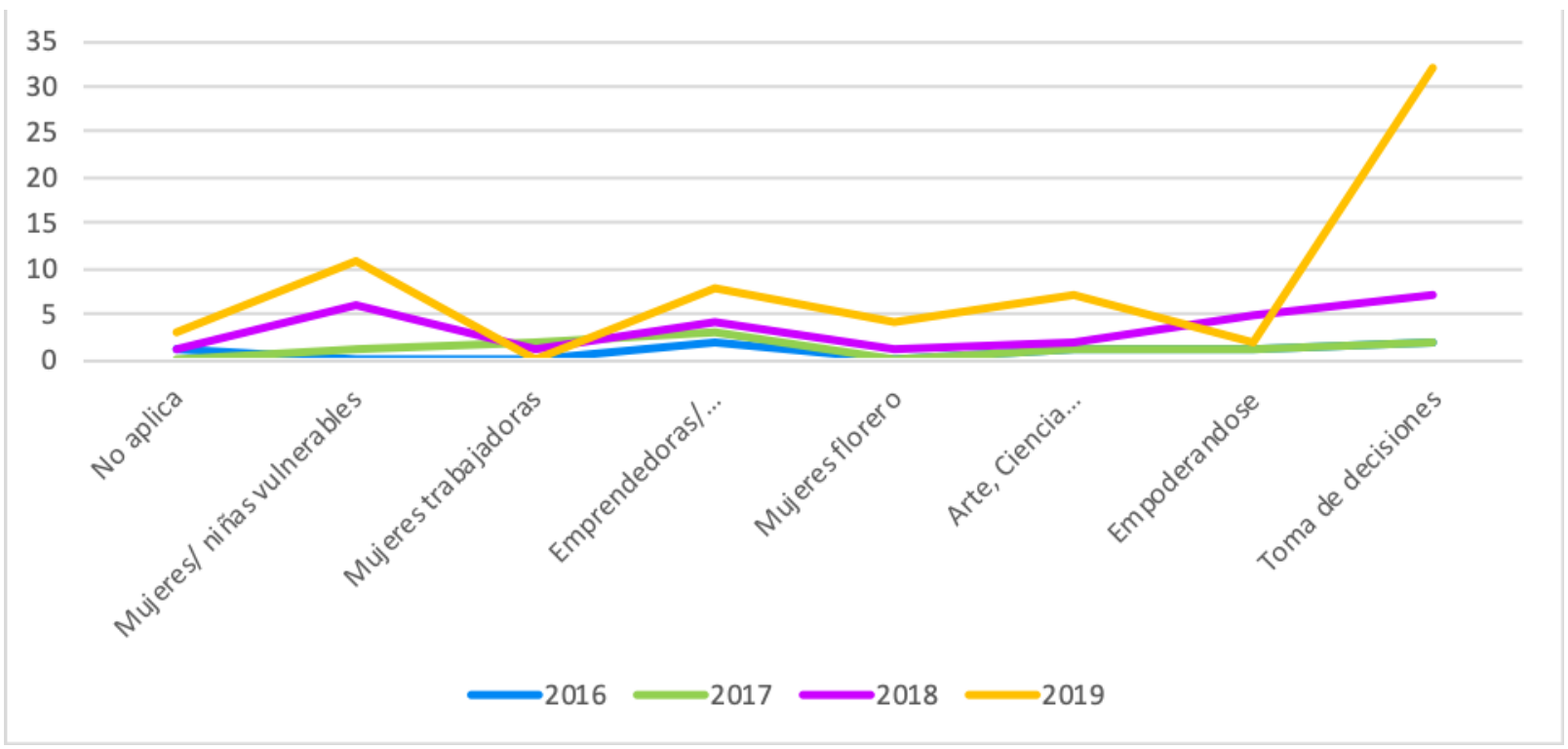

Gráfico 6. Rol de las mujeres en las publicaciones del MAEC.

Fuente: Elaboración propia

El gráfico 6 nos muestra el rol de las mujeres en la cuenta de Instagram del MAEC en relación al año de publicación, ya que, recordemos que este estudio se extiende de 2016 a 2019. Es de destacar que el contenido de la cuenta de Instagram del MAEC representa mayoritariamente a una mujer empoderada, generalmente en puestos de poder y con una participación activa en la práctica de la política exterior española. Se observa esta imagen de la mujer que toma decisiones especialmente a partir del 2018, con un incremento considerable en el 2019, como se aprecia en la gráfica anterior. Tal y como se especulaba en el planteamiento de la hipótesis, ello se debe al cambio

Vivat Academia. Revista de Comunicación. 2021, nº 154, 1-24 
Romero-Vara, L. y Parra-Parra, A.

Análisis de las publicaciones de la cuenta de Instagram del ministerio de asuntos exteriores y cooperación, desde una perspectiva de género

gubernamental suscitado en España, el cual instauró la paridad de género en los altos puestos de gobierno.

Además, es posible apreciar cómo las mujeres ocupan cada vez más altos cargos en gobiernos y organizaciones internacionales.

En segundo lugar, paradójicamente también se produce un aumento de las publicaciones que muestran a mujeres y niñas como vulnerables en el año 2019, pasando de cero publicaciones en 2016 a once en 2019. Finalmente, los roles menos representados en la cuenta del MAEC son los identificados como "mujer florero" solo cinco publicaciones en el período seleccionado- y mujer trabajadora, con un total de tres publicaciones - dos de ellas en 2017 y tan solo una en 2018-.

\subsection{Las temáticas}

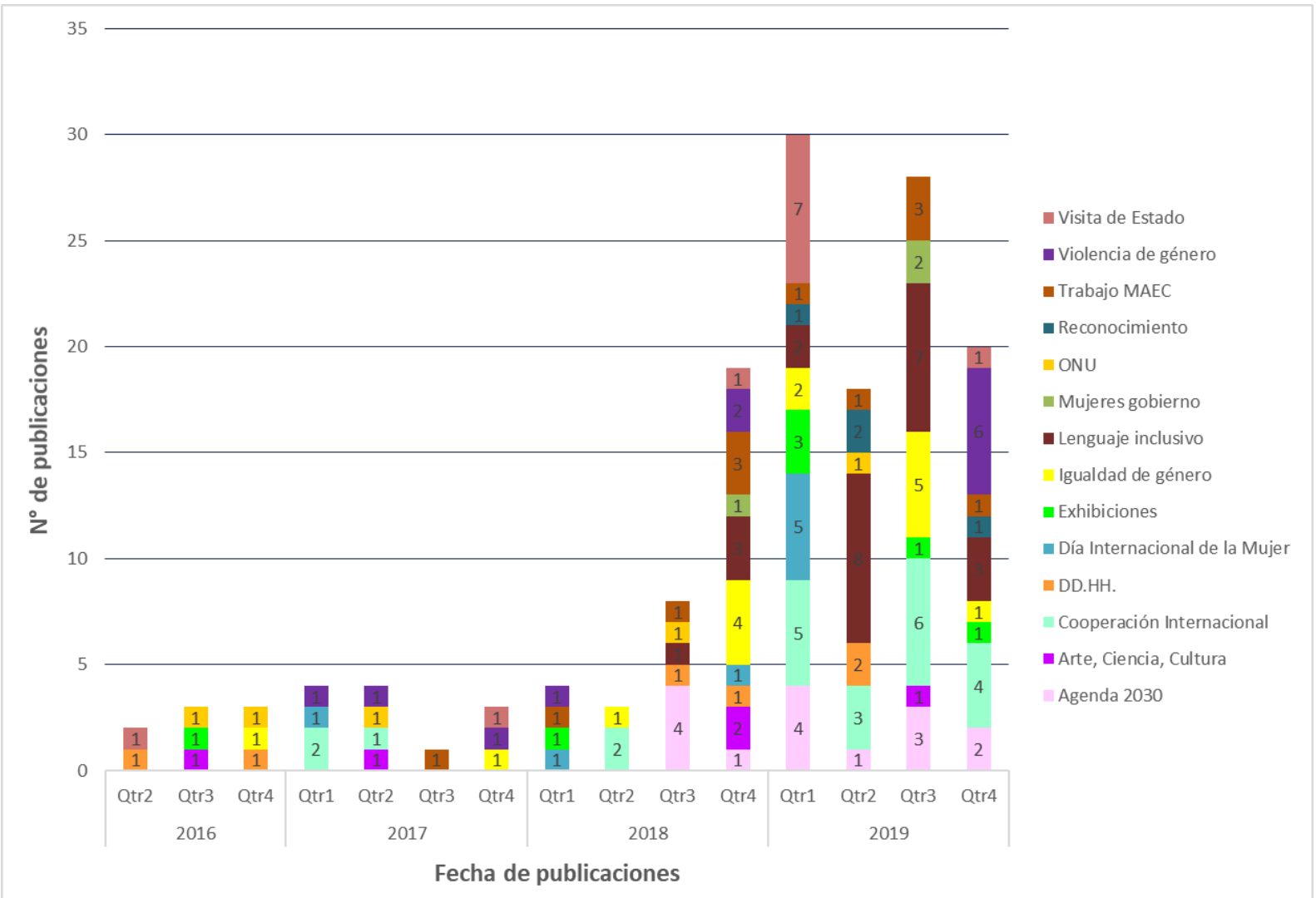

Gráfico 7. Temáticas que trata el perfil del MAEC sobre igualdad de género.

Fuente: Elaboración propia

A la cabeza de las categorías donde se encontró un número más alto de publicaciones que incluyen ña cuestión de género encontramos la utilización de un "Lenguaje inclusivo"; ello es generalmente es latente en las festividades regionales (ej. Día de la Comunidad de Madrid, Saint Jordi o de Castilla y León). En estas publicaciones generalmente no se muestra contenido audiovisual representando a la 
Romero-Vara, L. y Parra-Parra, A.

Análisis de las publicaciones de la cuenta de Instagram del ministerio de asuntos exteriores y cooperación, desde una perspectiva de género

población, ni a altos cargos, por lo que la inclusión es latente únicamente en el copy del post.

En segundo lugar, se encuentra el contenido referente a la "Cooperación Internacional", esta categoría se puede incluir dentro de uno de los pilares básicos de la diplomacia tradicional: "Promoción país", ya que en estas publicaciones el gobierno de España, a través del MAEC, promociona los programas de ayudas internacionales en los que participa, ya sea con fondos, con personal calificado o con iniciativas para mejorar la vida de mujeres y niñas alrededor del mundo, específicamente en países de escasos recursos o en conflicto.

Se observa que la cuenta de Instagram del MAEC hace hincapié en su participación conjunta con organizaciones internacionales como ONU o UNWomen a través de los programas de la AECID.

Las publicaciones del MAEC durante los últimos dos años, acentúan el compromiso adquirido por España en el 2015 para cumplir con los Objetivos de Desarrollo 2030, entre los que se encuentra alcanzar la igualdad de género. De acuerdo con la Agenda 2030 de la ONU, para el año 2030 se busca:

poner fin a todas las formas de discriminación contra las mujeres y niñas no es solo un derecho humano básico, sino que además es crucial para el desarrollo sostenible. Se ha demostrado una y otra vez que empoderar a las mujeres y niñas tiene un efecto multiplicador y ayuda a promover el crecimiento económico y el desarrollo a nivel mundial (ODS2030, 2015).

En el primer cuarto del último año (2019), los contenidos relacionados con el "Día Internacional de la Mujer" se incrementaron considerablemente. Ya se pronosticaba que la Huelga Nacional del 2018 en ese día se iba a repetir e iba a tener una gran repercusión mediática y social. Lo mismo sucedió con la categoría “Violencia de género", las publicaciones dirigidas a eliminar la violencia de género o ayudar a víctimas de esta en cualquier lugar del mundo a través de la red de consulados del MAEC se dispararon alrededor del 25 de noviembre de este año con motivo del Día Mundial contra la Violencia de Género.

\subsection{Contenido audiovisual, hashtags y emojis}

En cuanto al contenido audiovisual que el MAEC utiliza para la representación de género, es claro que se prima el uso fotografías únicas $(63,33 \%)$, antes que carruseles $(24,66 \%)$ o vídeos $(12 \%)$ como se puede apreciar en el gráfico 8 : 

cooperación, desde una perspectiva de género

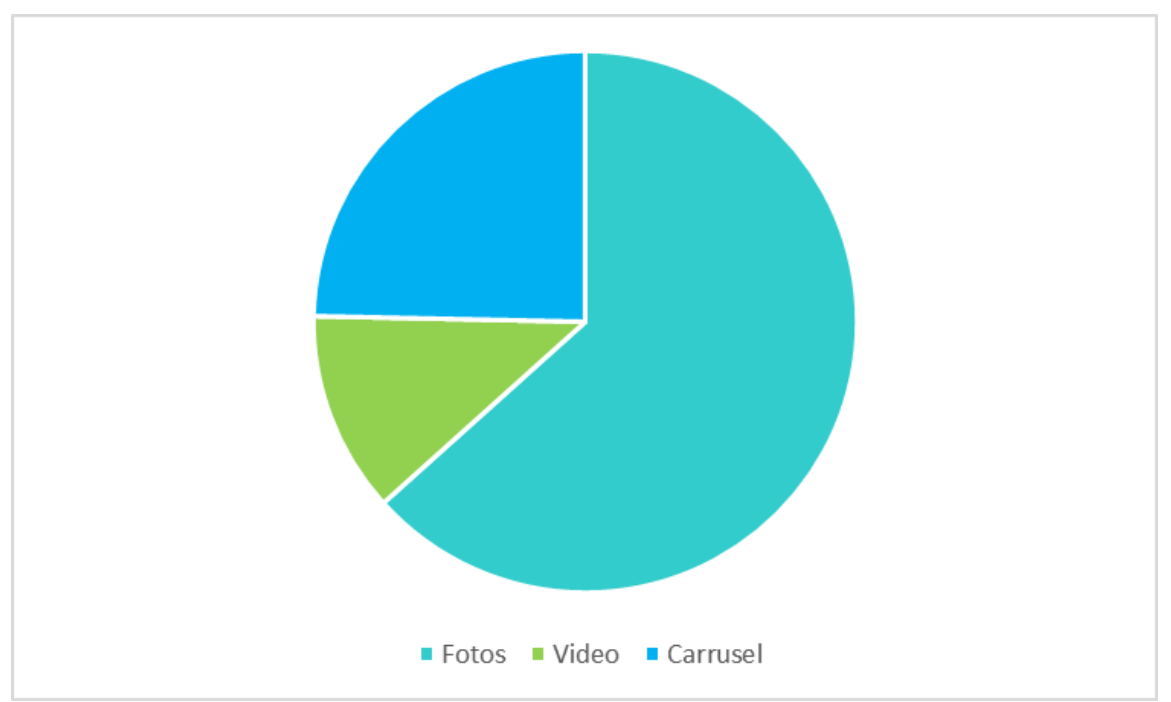

Gráfico 8. Contenido audiovisual en la cuenta del MAEC.

Fuente: Elaboración propia

En el periodo y muestra analizada, cabe destacar que en un $74 \%$ (111 publicaciones) del contenido audiovisual relacionado con la igualdad de género encontrado en la cuenta de Instagram del MAEC es posible encontrar presencia femenina. Por otro lado, en el $47 \%$ de los casos, dentro de las piezas se encuentran más mujeres que hombres frente a un $21 \%$ donde hay más hombres que mujeres. Existe un $32 \%$ de las publicaciones en las que podemos afirmar que la presencia de hombres y mujeres es equitativa, sin embargo, solo en un $13 \%$ aparecen personas, en el resto se ha identificado el uso de fotografías de paisajes o infografías. Por otra parte, no es posible entender la comunicación en redes sociales sin el uso de hashtags.

Estos conjuntos de palabras unidas por el símbolo almohadilla (\#) permiten la creación de comunidades alrededor de un tema de actualidad (Highfield et Leaver, 2015: 9), y a la vez, aumentan la visibilidad del contenido que los incluye. El MAEC es consciente de esto, por lo que en la mayoría de sus posts los utiliza. Solo en dos de las publicaciones analizadas no se encontró ningún hashtag (30 de enero de 2018 y 15 de noviembre de 2018). Los 10 hashtags más utilizados por el MAEC en su instagram en el periodo seleccionado son: \#España (42); \#Mujer (25); \#Agenda2030 (23); \#ODS (23); \#SomosCooperación (14); \#Cooperación (11); Igualdad (10); IgualdadDeGénero (10); \#CooperaciónEspañola (9); \#AECID (9).

\section{\#IgualdadDeGénero- \#Agenda2030- \#SomosCooperación- \#TúPuedesSerDiplomática}




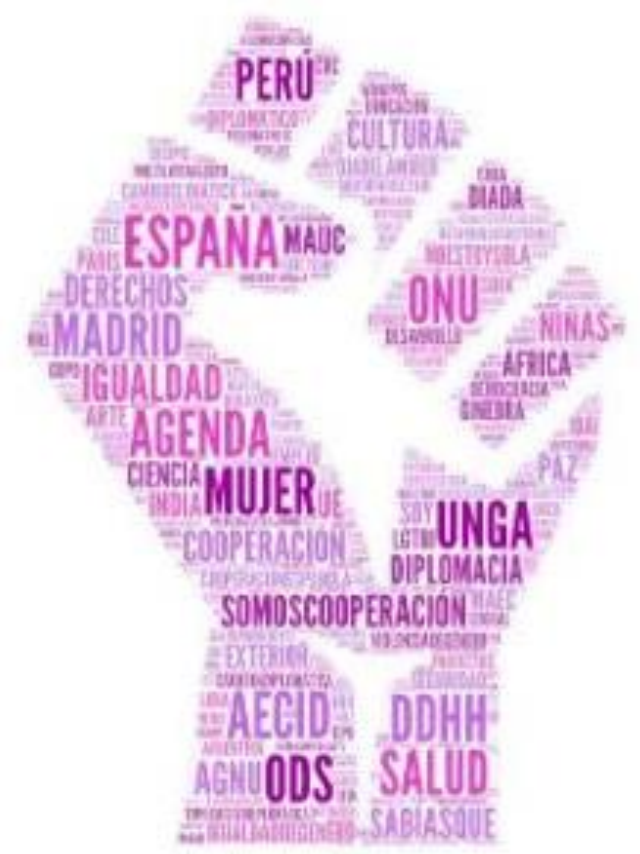

Imagen 4. Nube de hashtags utilizados por el MAEC en su cuenta de Instagram y relacionados con la igualdad de género.

Fuente: Elaboración propia

Los emoticonos o emojis son gráficos digitales que se han convertido en iconos de expresiones que ayudan a demostrar emociones, sentimientos, situaciones e inclusive marcar puntos. Los emojis son un elemento gráfico muy utilizado en las redes sociales. El MAEC en sus publicaciones en la cuenta de Instagram los utiliza en el $70 \%$ de sus publicaciones, de acuerdo con los resultados de la presente investigación. El top 10 de los encontrados en el análisis de las publicaciones relacionadas con la igualdad de género se puede observar en la imagen 5:

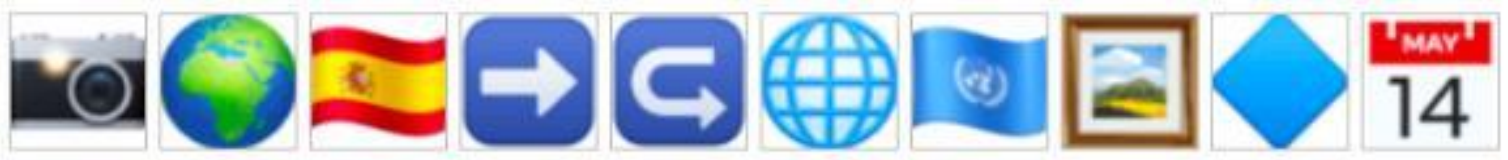

Imagen 5. Top 10 de los emojis más utilizados en las publicaciones relacionadas con la igualdad de género en el presente estudio.

Fuente: Elaboración propia.

Para terminar la sección de resultados, se considera importante mostrar un ejemplo de una publicación examinada, para que el lector comprenda cómo son utilizados los diferentes elementos del copy: hashtags, etiquetas, emoticonos y contenido audiovisual. La imagen 6 muestra un ejemplo muy completo. En la imagen se puede apreciar la representación que se hace de la mujer: se muestra igualdad de género, se proyecta una mujer con una participación política alta tomando decisiones que afectan las relaciones internacionales del momento. Esto se corrobora en el copy, 
Romero-Vara, L. y Parra-Parra, A.

Análisis de las publicaciones de la cuenta de Instagram del ministerio de asuntos exteriores y cooperación, desde una perspectiva de género

donde se menciona, con la ayuda de etiquetas, que esa mujer es la Directora General de la Unesco.
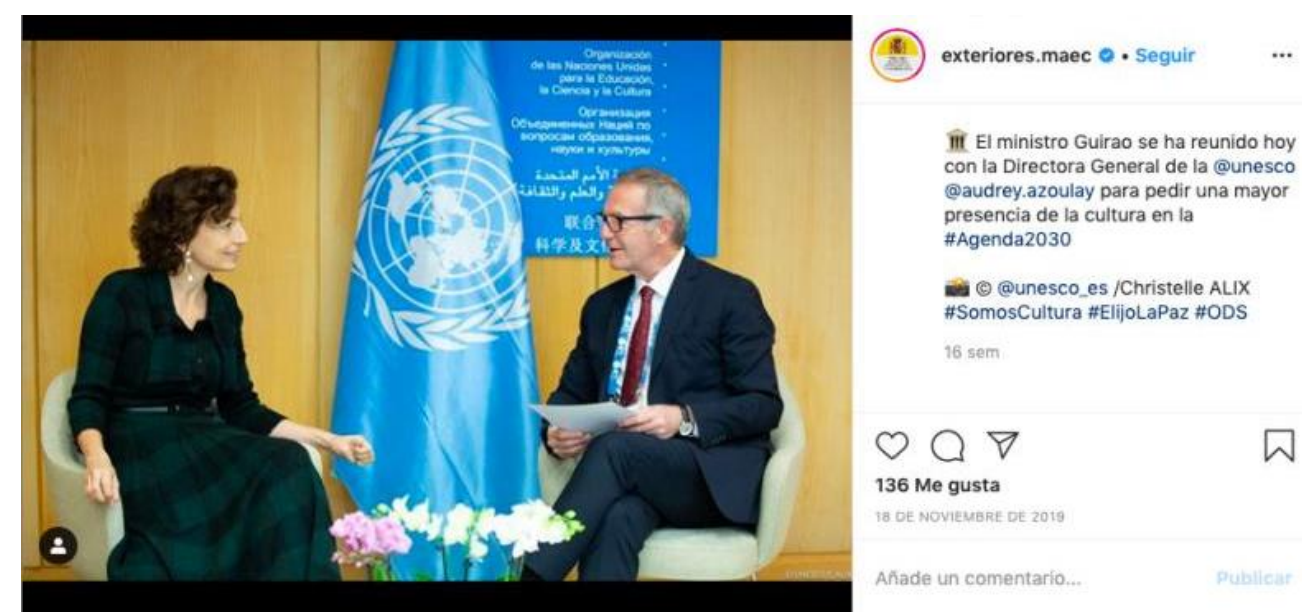

Imagen 6. Publicación del MAEC que muestra a la Directora General de la Unesco junto al ministro de Cultura, José Guirao.

Fuente: @exteriores.maec

El objetivo de utilizar emojis es hacer más visual el contenido textual y atraer la atención de los usuarios; por ejemplo, cuando la publicación se refiere a aspectos que afectan al mundo, se usa el mundo, para hablar de España, colocan la bandera, cuando se trata de cultura, la institucionalizan con un emoji de un edificio griego, y para dar crédito a la fotografía publicada se usa la cámara de fotos con el flash.

\section{CONCLUSIONES}

Al comienzo de este artículo se proponía un objetivo principal que solo se lograría alcanzar llevando a cabo un estudio pormenorizado de las publicaciones del MAEC en su cuenta de Instagram. Este objetivo no era otro que descubrir cómo representa el MAEC la igualdad de género en su cuenta de Instagram.

Podemos concluir que la representación de las mujeres en dicha cuenta de Instagram se hace en torno a las categorías que también se han recogido ya en este trabajo y que son:

1. Mujeres o niñas vulnerables.

2. Mujeres trabajadoras.

3. Mujeres emprendedoras o recibiendo educación o capacitación superior.

4. Mujer florero.

5. Mujeres artistas o científicas.

6. Mujeres empoderándose.

7. Mujeres en la toma de decisiones.

En este sentido es positivo mencionar que la tendencia de los posts a partir de 2019 es, sin duda, mostrar mujeres empoderándose y en situaciones de toma de 
Análisis de las publicaciones de la cuenta de Instagram del ministerio de asuntos exteriores y cooperación, desde una perspectiva de género

decisiones. Sobre esta última categoría hay que decir que las publicaciones durante los años anteriores son escasas, incluso nulas en el año 2016. Sin embargo, en el año 2019 también es significativamente alto el número de post que encajan en la categoría de "mujer florero". De hecho, ya se ha visto que el post con un mayor número de likes (470) y comentarios (6) es precisamente el que muestra la visita de Mauricio Macri a España, donde su esposa y la reina Letizia aparecen como meras acompañantes (véase imagen 1). Este tipo de publicaciones, que como vemos, tiene una gran aceptación entre la comunidad de seguidores de @exteriores.maec, debería replantearse ya que contribuye a perpetuar el estereotipo de la esposa del mandatario como mero adorno.

Es momento ahora de recoger la hipótesis planteada en el apartado dos del presente trabajo para confirmarla o refutarla. Recordemos que dicha hipótesis era: dos acontecimientos importantes ocurridos en España en el 2018, la celebración del 8M y la llegada al poder del gobierno socialista han sido artífices de una mayor atención del gobierno a la igualdad de género que tiene, entre otras muchas consecuencias, el aumento del número de publicaciones con presencia femenina. Esta hipótesis queda confirmada si atendemos a la siguiente tabla:

Tabla 2. Número de publicaciones con presencia femenina en el Instagram del MAEC en los años 2016, 2017, 2018 y 2019.

\begin{tabular}{|c|c|c|c|}
\hline Año 2016 & Año 2017 & Año 2018 & Año 2019 \\
\hline 9 & 12 & 34 & 96 \\
\hline
\end{tabular}

Fuente: Elaboración propia.

Precisamente, en el año 2018 las publicaciones aumentan un 183,33\% respecto al año anterior. Y este incremento se mantiene en el paso de 2018 a 2019, con un porcentaje de aumento de publicaciones con presencia femenina de un $182,35 \%$.

Queda claro que desde la llegada del gobierno socialista las publicaciones con presencia femenina han aumentado. Sin embargo, en la hipótesis también se menciona que la celebración del 8-M en 2018, Día Internacional de la Mujer, ha contribuido de alguna manera a que las publicaciones con presencia femenina aumenten en la cuenta de Instagram que es objeto de estudio. Pues bien, en el año 2016 no hubo ninguna referencia a este día porque la cuenta no existía; veamos qué ocurrió en los años 2017, 2018 y 2019. En primer lugar, en 2017 se conmemora este día con una sola publicación, que alude a la Agenda 2030 y al compromiso de la Comunidad Internacional para la consecución de la igualdad de género.

En 2018, también se hace una publicación celebrando la fecha tan señalada. En este caso, se opta también por destacar los objetivos igualdad, empoderamiento y eliminación de la discriminación contra la mujer. Recordemos que el 8 de marzo de 
Romero-Vara, L. y Parra-Parra, A.

Análisis de las publicaciones de la cuenta de Instagram del ministerio de asuntos exteriores y cooperación, desde una perspectiva de género

2018 no había tenido lugar la moción de censura que acabó con la llegada al poder del gobierno socialista.

Por último, en el año 2019 es posible comprobar que las publicaciones que celebran el Día Internacional de la Mujer aumentan significativamente, de hecho, la conmemoración de este día comienza una semana antes con una publicación que inaugura la etiqueta \#tiempodemujeres y se dedica a las mujeres relacionadas con la diplomacia. El 4 de marzo encontramos tres publicaciones relacionadas con el 8-M. La primera de las publicaciones de este día anunciaba el programa de actividades conmemorativas; la segunda muestra la presentación de dicho programa de actividades por parte del ministro Josep Borrell junto a destacadas mujeres de la cultura y del propio Ministerio de Exteriores. Y el tercer y último post del día 4 de marzo es un video teaser de testimonios de diplomáticas. El día 8 de marzo la publicación que celebra este día trata de recordar que la igualdad de género es el ODS5 y el apoyo que el MAEC hace de la Agenda de Mujeres, Paz y Seguridad de las Naciones Unidas.

Efectivamente, como vemos, desde la celebración del 8-M en 2018, han aumentado las publicaciones del MAEC en Instagram sobre la igualdad de género.

Es importante mencionar también que las publicaciones relacionadas con la igualdad de género en la cuenta del MAEC giran alrededor de tres ejes principales: programas de cooperación en los que la AECID colabora en Medio Oriente, África y Latinoamérica; medidas adoptadas por el gobierno en la línea de cumplir con los ODS2030; y finalmente, la incorporación de las mujeres en puestos gubernamentales y diplomáticos en España.

Se concluye que, aunque en el último año se puede observar un aumento considerable en las publicaciones relacionadas con la igualdad de género en la cuenta de Instagram del MAEC, siguen siendo pocas y se centran en la celebración o conmemoración de fechas clave como es el Día Internacional de la Mujer o el Día Internacional de la Eliminación de la Violencia contra la Mujer.

\section{REFERENCIAS}

Añazco Defaz, G. D. L. M. (2018). Presencia de la mujer en la diplomacia. Una perspectiva feminista de las relaciones internacionales: el caso Ecuador 2000-2017 (Master's thesis, Universidad Andina Simón Bolívar, Sede Ecuador). http://repositorionew.uasb.edu.ec/bitstream/10644/6225/1/T2656-MRIA\%C3\%B1azco-Presencia.pdf

Ayuso, S. (2019). ¿Primeras damas o damas florero con pimientos? El País. https://elpais.com/sociedad/2019/08/31/actualidad/1567267213_285863.html 
Romero-Vara, L. y Parra-Parra, A.

Análisis de las publicaciones de la cuenta de Instagram del ministerio de asuntos exteriores y cooperación, desde una perspectiva de género

Equal Measures 2030. (2019). Harnessing the power of data for gender equality. Introducing the 2019 EM2030 SDG Gender Index. https://www.equalmeasures2030.org/wpcontent/uploads/2019/07/EM2030_2019_Global_Report_English_WEB.pdf

Finkel Morgenstern, L., \& Gordo López, Á. J. (2019). Redes sociales, mujeres y marcas. Una aproximación Netnográfica. Espacio abierto cuaderno venezolano de sociología, 28(3), 25-45. https://eprints.ucm.es/57193/1/Espacio-abierto-28-3_Art2_FINKELyGORDO.pdf

Highfield, T., \& Leaver, T. (2015). A methodology for mapping Instagram hashtags. First Monday, 20(1), 1-11. https://eprints.qut.edu.au/79684/3/_staffhome.qut.edu.au_staffgrouph\%24_hol lambc_Desktop_A\%20Methodology\%20for\%20Mapping\%20Instagram\%20Hashta gs_submission.pdf

Locher, B. (1998). Las relaciones internacionales desde la perspectiva de los sexos. Nueva Sociedad, 158, 40-62. http:// biblioteca.hegoa.ehu.es/downloads/7005/\%2Fsystem $\% 2 F p d f \% 2 F 1476 \% 2 F$ Relaciones_Internacionales_desde_la_Perspectiva_de_los_Sexos.pdf

Lozano Vázquez, A. (2012): “El Feminismo en la teoría de Relaciones Internacionales: un breve repaso", en Revista de Relaciones Internacionales de la UNAM, vol. 14. pp. 143-152.

Marchand, M. H. (2016): “Género y Relaciones Internacionales: Una mirada feminista "postcolonial" desde América Latina", en Introducción a las Relaciones Internacionales: América Latina y la política global. Oxford: Ciudad de México.

Martínez, S. (2018). El Gobierno de Pedro Sánchez bate el récord de paridad en Europa. El Periódico. https://www.elperiodico.com/es/politica/20180606/paridad-gobiernoseuropeos-6861276

ONU. (NA). Objetivo 5. Igualdad de Género. https://www.undp.org/content/undp/es/home/sustainable-developmentgoals/goal-5-gender-equality.html

Peña Villarroel, Y. (2007). Los aportes de las teorías feministas a la comprensión de las relaciones internacionales. Politeia, 30(39), 65-86. https://www.redalyc.org/pdf/1700/170018341003.pdf

Rabaneda, P. \& Martínez, A. (2015). El I Congreso Internacional de Mujeres, La Haya, 1915. Un hito para la cultura de paz cien años después. Arenal: Revista de historia de mujeres, 22(1), 191-209.

https:// dialnet.unirioja.es/descarga/articulo/5291010.pdf 
Análisis de las publicaciones de la cuenta de Instagram del ministerio de asuntos exteriores y cooperación, desde una perspectiva de género

Rincón, A. (2019). Activismo, co-creación e igualdad de género: la comunicación digital en la huelga feminista del 8M. Revista Dígitos, (5), 56-74. https://revistadigitos.com/index.php/digitos/article/download/142/78

Ruiz, P. (2015). La transferencia de políticas globales de género y su puesta en agenda. Revista Opera, (16), 55-75. https://revistas.uexternado.edu.co/index.php/opera/article/download/4141/44 $\underline{85 / 0}$

Sen, C. (2019) ¿Igualdad de género en el 2030? Ningún país la tendrá, ni siquiera Dinamarca. Vanguardia. https://www.lavanguardia.com/vida/20190604/462661545490/igualdad-degenero-paises-informe-ranking.html

Tena, B. (2019) ¿Es España el país más feminista del mundo? El Confidencial. https://www.elconfidencial.com/espana/2019-03-08/8m-espana-feminismomachismo-paro-brecha-salarial_1864982/

Thompson, L. \& Clement, R. (2019). Definiendo la política exterior feminista. International Center for Research on Women. https://www.icrw.org/wpcontent/uploads/2019/11/ICRW_DefiningFeministForeignPolicy_Brief_Spanish. pdf

Tickner, J. A. \& True, J. (2018). A Century of International Relations Feminism: From World War I Women's Peace Pragmatism to the Women, Peace and Security Agenda, International Studies Quarterly, Volume 62, Issue 2, 221-233, https://doi.org/10.1093/isq/sqx091

Villaplana, V. \& León, A. (2019). Transfeminidad viral en la cultura red. Memes, videoclips en la construcción social de la narco estética buchona y choni. En Suárez, Juan Carlos; Marín, Sergio; Panarese, Paola. (2019). TRANSFEMINIDAD VIRAL EN LA CULTURA RED. MEMES, VIDEOCLIPS EN LA CONSTRUCCIÓN SOCIAL DE LA. Dykinson eBook, 290. https://www.academia.edu/download/59191917/Actas_congreso_ComGen_Sev illa20190509-1484-6ig9sv.pdf\#page $=290$

World Economic Forum. (2018). The global gender gap report 2018. World economic forum. Cologny/Geneva. http://www3.weforum.org/docs/WEF_GGGR_2018.pdf

\section{AUTORAS}

\section{Laura Romero Vara}

Facultad de CC. De la Información, Universidad Complutense de Madrid, España. 
Romero-Vara, L. y Parra-Parra, A.

Análisis de las publicaciones de la cuenta de Instagram del ministerio de asuntos exteriores y cooperación, desde una perspectiva de género

Licenciada en Relaciones Internacionales por la Universidad del Valle de México. Máster en Comunicación Social y doctoranda en Periodismo por la Universidad Complutense de Madrid, actualmente estoy becada por el CONACYT (México). Mi investigación está relacionada con la implementación de las tecnologías de la información en las relaciones internacionales y diplomáticas. Además, me interesa la comunicación política y de organizaciones internacionales en el ciberespacio.

laurom05@ucm.es

Orcid ID: https:/ / orcid.org/0000-0003-1962-2750

Google Scholar: https://scholar.google.com/citations?user=yLLppm8AAAAJ\&hl

\section{Alicia Parras-Parras}

Facultad de CC. De la Información, Universidad Complutense de Madrid, España.

Alicia Parras es doctora en Comunicación Social (Premio Extraordinario de Doctorado, 2015) y profesora ayudante doctor en la Unidad Departamental de Documentación en la Facultad de Ciencias de la Información de la UCM. Su principal línea de investigación es el tratamiento documental y los procesos informativos, culturales y estéticos de la fotografía contemporánea sobre lo que ha escrito varios capítulos de libros y artículos científicos. Ha sido visiting Scholar en UCLA, participado en numerosos congresos nacionales e internacionales y comisariado varias exposiciones sobre fotografía, entre los que destaca el proyecto We don't care anymore, un colectivo internacional de artistas femeninas. Es miembro del grupo de investigación UCM-GR17-970831 Patrimonio Digital en Medios de Comunicación (PaDem).

aparras@ucm.es

Índice $\mathrm{H}: 3$

Orcid ID: https://orcid.org/0000-0002-7186-1065

Google Scholar: https://scholar.google.es/citations?user=KWHej90AAAAJ\&hl=es

Scopus ID: https://www.scopus.com/authid/detail.uri?authorId=54956648500

Academia.edu: https://ucm.academia.edu/AliciaParras 